BEAM LOADING ANALYSIS of the BOOSTER RF SYSTEM

BOOSTER TECHNICAL NOTE

NO. 191

M. METH and A. RATTI

APRIL 1, 1991

ALTERNATING GRADIENT SYNCHROTRON DEPARTMENT BROOKHAVEN NATIONAL LABORATORY

UPTON, NEW YORK 11973 


\title{
Beam Loading Analysis of the Booster RF System.
}

\author{
M. Meth
}

A. Ratti

\section{Introduction}

This note summarizes the results of measurements and design changes made during the construction phase of the Booster Band III RF system. A substantial change occurred in the injection scenario. Instead of a continuous beam, the beam is chopped at a $2.5 \mathrm{MHz}$ rate and injected in a multiturn scheme lasting approximately $150 \mu \mathrm{s}$. A second change is the reduction of the cavity capacitance, which was necessitated to increase the frequency response of the cavity tuning system. The lumped capacitance is reduced from $300 \mathrm{pF}$ to $200 \mathrm{pF}$ per gap; the total capacitance from $450 \mathrm{pF}$ to $350 \mathrm{pF}$ per gap.

The stored energy in the cavity is decreased, increasing the susceptibility of the system to interacting with a high current beam. Both transient and steady state beam loading effects are considered and evaluated within the system installed for the commissioning of the Booster.

\section{System model.}

The conventional model of the system is to represent the cavity as a tank circuit, as seen by the beam or as seen by the power amplifier.

\section{Model as seen by the BEAM.}

The cavity model as seen by the beam is shown in Fig. 1. The gap capacitance was measured to be $900 \mathrm{pF}$ at the bus bars that connect the two gaps in parallel. We assume that each gap contributes $350 \mathrm{pF}$. Since the beam sees the two gaps in series, the total cavity equivalent capacitance is $175 \mathrm{pF}$.

The inductance required to resonate Band III, varies from 23.16 to $8.2 \mu \mathrm{H}$, as the cavity tunes from 2.5 to $4.2 \mathrm{MHz}$.

The shunt impedance is calculated from bandwidth measurements. In our case the measured Q, obtained by detuning the cavity to the $3 \mathrm{~dB}$ points is 20 , when the gap voltage is $22.5 \mathrm{kV}$ and at a frequency of $2.5 \mathrm{MHz}$. From this, we can calculate the shunt impedance $\mathrm{R}_{\mathrm{sh}}$ as:

$$
\mathrm{R}_{\mathrm{sh}}=\mathrm{Q} / \omega \mathrm{C}=7.275 \mathrm{k} \Omega
$$

A few caveats are now needed. The bandwidth measurements are meaningful only in a linear system. In this case measurements are made at the injection frequency since the system is far from the Q-loss limitation that occurs at higher frequencies. Even though we have observed that 
by sweeping the cavity the losses increase by a factor of two, we remember that at injection $f$ dot is very small and the dynamic effects are therefore not so dramatic. Furthermore, the measurement of the bandwidth at higher voltages and higher biasing levels is questionable, since the resonance curve may not be symmetric around the resonant frequency.

From calorimetric measurements of cavity dissipation and the measurement of $R_{\mathrm{sh}}$ at $2.5 \mathrm{MHz}$, we can estimate $\mathrm{R}_{\mathrm{ab}}$ at $4.2 \mathrm{MHz}$ and calculate the average value of the tube damping resistance. The $\mathrm{CW}$ dissipation of the cavity for $\mathrm{V}=45 \mathrm{kV}$ at injection and extraction frequencies are :

freq

$2.5 \mathrm{MHz}$

$4.2 \mathrm{MHz}$
$\underline{\mathrm{CW} \text { dissipation } \mathrm{P}}$

$29.8 \mathrm{~kW}$

$72.0 \mathrm{~kW}$

the ferrite shunt resistance is:

$$
R_{\text {ceriic }}=\frac{V^{2}}{2 P}=33.75 \mathrm{k} \Omega \text { at } 2.5 \mathrm{MHz}
$$

The average tube resistance is calculated as:

$$
\begin{aligned}
& 1 / R_{\text {tube }}=1 / R_{\text {sh }}-1 / R_{\text {ferrite }} \\
& R_{\text {tube }}=9.25 \mathrm{k} \Omega
\end{aligned}
$$

The ferrite shunt resistance is $14.06 \mathrm{k} \Omega$ at $4.2 \mathrm{MHz}$. The shunt resistance $R_{\text {,h }}$ is $5.58 \mathrm{k} \Omega$ at 4.2 MHz. Knowing the shunt impedance and the total gap voltage, it is possible to calculate the amplifier output current.

$I_{g e n}=V_{g} / R_{a h}=6.18 \mathrm{~A}$ at $2.5 \mathrm{MHz}$, and

$\mathrm{I}_{\mathrm{gen}}=8.06 \mathrm{~A}$ at $4.2 \mathrm{MHz}$.

\section{Model as seen by the POWER AMPLIFIER.}

The cavity model as seem by the power amplifier is shown in Fig. 2, which is very similar to Fig. 1, and can be used with the proper change in parameters to represent the scenario on which the Power Amplifier will have to work. In this case, the two gaps are seen in parallel. The total

1 loss measurement at $45 \mathrm{kV}$ are projected from measurements obtained at voltages up to $40 \mathrm{kV}$ - see Appendix A. 
cavity capacitance is then $700 \mathrm{pF}$, and the equivalent inductance varies from 5.8 to $2.05 \mu \mathrm{H}$. Similarly we can assume that the shunt impedance of this circuit varies from $1.82 \mathrm{k} \Omega$ to 1.39 $\mathrm{k} \Omega$, since the drive loop couples one stack of ferrite, we achieve a $2: 1$ step up transformation, which reflects in a $4: 1$ ratio in the impedances. The current required to obtain $22.5 \mathrm{kV}$ across the gaps varies from $12.36 \mathrm{~A}$ to $16.12 \mathrm{~A}$.

This circuit will be loaded by a beam current which is twice the actual beam, since it will simultaneously see the effect of both gaps.

\section{Steady State Beam Loading}

In order to estimate the operating conditions of the system and the beam loading effects, it is important to calculate the circulating beam current both at injection and extraction.

The average beam current is:

$\mathrm{I}_{\mathrm{in}}=\mathrm{n} * \mathrm{q} * \mathrm{f}=7.510^{12} * 1.610^{-19} * 2.510^{6}=3 \mathrm{~A}$ at injection, and

$\mathrm{I}_{\mathrm{ent}}=5.04 \mathrm{~A}$, at extraction.

Since the beam will have bunches that are almost 180 degrees long, we can assume that they are a half sinusoid. The spectral components are known [1]:

$\mathrm{I}_{\mathrm{bin}}=\pi / 2 * \mathrm{I}_{\mathrm{avg}}=4.71 \mathrm{~A}$ and

$\mathrm{I}_{\text {bext }}=7.91 \mathrm{~A}$

are the fundamental currents at injection and extraction, whereas the peak currents are respectively:

$\mathrm{I}_{\mathrm{plin}}=\pi * \mathrm{I}_{\mathrm{avg}}=9.42 \mathrm{~A}$ and

$I_{p l e x t}=15.83 \mathrm{~A}$.

The effects of beam loading at steady state depend upon the ratio of the beam current $\mathrm{I}_{\mathrm{b}}$ and the amplifier fundamental current $\mathrm{I}_{0}[2]$. This ratio is:

$\mathrm{Y}_{\mathrm{in}}=\mathrm{I}_{\mathrm{b}} / \mathrm{I}_{0}=4.71 / 6.18=0.76$ at injection and

$\mathrm{Y}_{\text {ext }}=7.91 / 8.06=0.98$ at extraction

For the case of steady state beam loading stability requires that $\mathrm{Y}$ be less than two, and this calculation shows that the limit is not exceeded. 
One possible mode of operation requires that the cavity be detuned prior to injection such that the power amplifier drives a real load after the beam has entered the Booster. The level of the detuning depends on the quadrature component of beam current and is expressed in terms of an equivalent tuning capacitance or change in resonant frequency.

$$
\begin{aligned}
\Delta \mathrm{C}_{\mathrm{inj}} & =-\mathrm{I}_{\mathrm{b}} \cos \phi / \omega * \mathrm{~V}_{\mathrm{s}}=-6.7 \mathrm{pF} \text { at injection and, } \\
& =-5.78 \mathrm{pF} \text { at extraction. }
\end{aligned}
$$

This means that the cavity will have to be tuned to a higher resonant frequency. It is important to estimate the detuning both in terms of frequency and tuning current.

Since the capacitance varies inversely with the square of the frequency,

$$
\begin{aligned}
& \Delta \mathrm{F}=\mathrm{F} / 2 * \Delta \mathrm{C} / \mathrm{C}=47.75 \mathrm{kHz} \text { at injection and } \\
& \Delta \mathrm{F}=69.3 \mathrm{kHz} \text { at extraction }
\end{aligned}
$$

Assuming that the tuning current varies linearly with frequency and knowing that the tuning current varies from 100 to $900 \mathrm{~A}$, we estimate the offset in tuning current as:

$$
\begin{aligned}
& \Delta \mathrm{I}=\Delta \mathrm{F} / \Delta \mathrm{F}_{\text {tot }} * \Delta \mathrm{I}_{\text {tox }}=47.75 / 1700 * 800=22.4 \text { A at injection, and } \\
& \Delta \mathrm{I}_{\text {ext }}=32.7 \text { A at extraction. }
\end{aligned}
$$

The power factor angle at which the amplifier operates at injection, is calculated as

$$
\tan ^{-1}\left(I_{\mathrm{b}} / \mathrm{I}_{0}\right)=\tan ^{-1}(4.71 / 6.18)=37.3^{\circ}
$$

The steady state beam loading parameters have been calculated and are summarized in Table 1.

\section{Transient beam loading}

Transient effects have also been considered. The beam at injection will behave as shown in Fig 3 , that is a sequence of pulses of growing amplitude. The injection will last approximately 150 $\mu \mathrm{s}$, or about 120 turns. During this time the cavity and power amplifier will see this "perturbation" and the tuning loops will have to correct for it.

Each microbunch injected from the linac will have a charge of about

$$
\mathrm{Q}_{\mu \mathrm{b}}=\mathrm{n} * \mathrm{q} * 3 / 360=1 * 10^{-8} \text { Coul. }
$$

The cavity time constant is calculated from the circuit model in Fig. 1 to be:

$$
\tau=2 \mathrm{R} \mathrm{C}=2.58 \mu \mathrm{s}
$$


Since nine microbunches will be injected during one cavity time constant, the total amount of beam charge injected in this time is:

$$
\mathrm{Q}=9 * \mathrm{Q}_{\mu \mathrm{h}}=9 * 10^{-8} \text { Coul. }
$$

The maximum gap CV product [4] for a gap voltage of $45 \mathrm{kV}$ is

$$
\mathrm{CV}=17510^{-12} * 4510^{3}=7.87510^{-6} \mathrm{Coul}
$$

Therefore the phase shift induced by the beam during one cavity time constant is

$$
\mathrm{Q} / \mathrm{CV}=1.1410^{-2} \mathrm{rad}=0.66^{\circ}
$$

This scenario has been simulated using the circuit analysis program PSPICE as shown in Fig 4. After the cavity has reached its steady state, a train of pulses of growing amplitude is injected in quadrature with the amplifier current. This does not show any significant phase shift or amplitude modulation and confirms our expectations.

At injection the gap voltage will be lower than $45 \mathrm{kV}$. It is possible to see that the beam induced phase shift in a cavity time constant will be less than seven degrees for a gap voltage as low as $4 \mathrm{kV}$.

An important factor is the tuning system time constant: the faster the tuning system can react to the beam induced detuning, the less will be the total phase shift.

The time constant of the transistor bank that provides the cavity tuning current and its related circuitry has been measured under rf by introducing a perturbation of approximately 30 degrees in the phase detector and looking at the response of the feedback loop. Fig 5 shows the results of this measurement, and indicates that it takes approximately 100 microseconds to restore the tuning condition. This time is less than the injection period and is definitely an encouraging result. Fig 6 confirms this, showing the measured open loop frequency response of the transistor bank. The closed loop bandwidth is projected to be greater than $10 \mathrm{kHz}$ for tuning currents as large as $750 \mathrm{~A}$. At injection the tuning current is approximately $150 \mathrm{~A}$ and the closed loop bandwidth is estimated as $15 \mathrm{kHz}$.

\section{Tube resistance}

An important side issue results from the cavity model is the evaluation of the average output resistance of the power amplifier and the plate resistance of the EIMAC 4CM300,000 tetrode.

From the $3 \mathrm{~dB}$ bandwidth measurements at $2.5 \mathrm{MHz}$ and calorimetric measurement of cavity dissipation at the same frequency, the average tube resistance was calculated as $9.25 \mathrm{k} \Omega$. Measurements were performed at $45 \mathrm{kV}$ and the output resistance is referred to the $45 \mathrm{kV}$ level. To transfer this resistance to the tube $(11.25 \mathrm{kV}$ level $)$, scale by a factor of 16 . The amplifier 
output resistance is $578 \Omega$. The tube operates class B, conducting for one half period of each if cycle. The avcrage plate resistance is $290 \Omega$.

Plate resistance varies inversely with the cube root of plate current. This measurement is at a peak plate current of $20 \mathrm{~A}$. For comparison purposes, in the conceptual design of the power amplifier the average plate resistance was estimated [5] (from constant current characteristics) as $186 \Omega$ at a peak plate current of $65 \mathrm{~A}$.

\section{Appendix A}

Ferrite losses were calorimetrically measured at a cavity voltage of $40 \mathrm{kV}$ over the full frequency range. At $45 \mathrm{kV}$ loss measurements were obtained for frequencies up to $3.0 \mathrm{MHz}$; at higher frequencies $\mathrm{Q}-$ loss limits $\mathrm{CW}$ measurements.

The results are summarized below.

$\begin{array}{ccc}\begin{array}{c}\text { Frequency } \\ {[\mathrm{MHz}]}\end{array} & \text { Cavity Voltage } & \frac{\text { Cavity losses }}{[\mathrm{KW}]} \\ 2.4 & 30 & \\ & 40 & 11.1 \\ & 45 & 26.2 \\ 3.0 & 30 & 41.5 \\ & 40 & 10.6 \\ & 45 & 26.9 \\ 3.6 & 30 & 49.5 \\ & 40 & 12.7 \\ & 45 & 40.0 \\ 4.2 & 30 & -\cdots \\ & 40 & 12.7 \\ & 45 & 36.0\end{array}$




\section{References}

[1] M. Meth, A. Ratti - Push pull operation of the rf cavity - Booster T.N. 84, 7/87.

[2] F. Pedersen - Beam loading effects in the CERN PS Booster - IEEE Tr. Nu. Sci., v. NS22, no. 3, p. 1906-9, (1975)

[3] M. Puglisi - Beam loading compensation and Robinson instability limit - Booster T. N. $88,8 / 87$.

[4] M. Meth, A. Ratti - Time domain beam loading studies of the Booster and AGS Proceedings of the 1989 IEEE Particle Accelerator Conference, Chicago 1989, 186-9.

[5] M. Meth, A. Ratti - Specification and design of if power amplifier for proton cavity Booster T. N. 92, 9/87

[6] E. Raka - RF beam loading in the Booster - Booster T. N. 12, 2/86

[7] K. W. Robinson - Electron ring accelerator effects - CEAL-TM-182, Cambridge, Mass. (1969)

\section{Acknowledgements:}

The authors would like to acknowledge all of those who contributed to the work presented here. Particularly R. T. Sanders, who leads the Project, D. Kasha and W. Eng, who engineered the tuning system, and $R$. Spitz who built the required parts and did the measurements. 


\begin{tabular}{||l|c|c||}
\hline \multicolumn{1}{|c|}{ PARAMETER } & INJECTION & EXTRACTION \\
\hline Frequency & $2.5 \mathrm{MHz}$ & $4.2 \mathrm{MHz}$ \\
\hline $\begin{array}{l}\text { Amplifier Drive } \\
\text { Current Ig } \\
\text { Peak of Fundamental }\end{array}$ & $24.72 \mathrm{~A}$ & $32.24 \mathrm{~A}$ \\
\hline $\begin{array}{l}\text { Beam Current } \\
\text { Average } \\
\text { Peak of Fundamental }\end{array}$ & $3 \mathrm{~A}$ & $5.04 \mathrm{~A}$ \\
\hline $\mathrm{Y}=\mathrm{I}_{\mathrm{b}} / \mathrm{I}_{\mathrm{g}}$ & $4.71 \mathrm{~A}$ & $7.91 \mathrm{~A}$ \\
\hline$\Delta \mathrm{C}$ & .76 & .98 \\
\hline$\Delta \mathrm{F}$ Resonance & $-6.7 \mathrm{pF}$ & $-5.78 \mathrm{pF}$ \\
\hline$\Delta \mathrm{I}$ Tuning & $47.75 \mathrm{Khz}$ & $69.3 \mathrm{Khz}$ \\
\hline $\mathrm{R}_{\text {thunt }}$ & $22.4 \mathrm{~A}$ & $32.7 \mathrm{~A}$ \\
\hline Synchronous Phase Angle & $7.27 \mathrm{~K} \Omega$ & $5.5 \mathrm{~K} \Omega$ \\
\hline
\end{tabular}

\section{Table I}

Summary of Beam Loading Calculations

$\mathrm{C}=175 \mathrm{pF}$

$\mathrm{n}=7.5 \cdot 10^{12}$ Particle/Bunch 


\begin{tabular}{|c|c|}
\hline$f=2.5 \mathrm{MHz}$ & $f=4.2 \mathrm{MHz}$ \\
\hline $\mathrm{L} 23.16 \mu \mathrm{H}$ & $8.2 \mu \mathrm{H}$ \\
\hline $\mathrm{R} \quad 7.2 \mathrm{k} \Omega$ & $5.58 \mathrm{k} \Omega$ \\
\hline$I_{q} \quad 6.18 \mathrm{~A}$ & $8.06 \mathrm{~A}$ \\
\hline
\end{tabular}

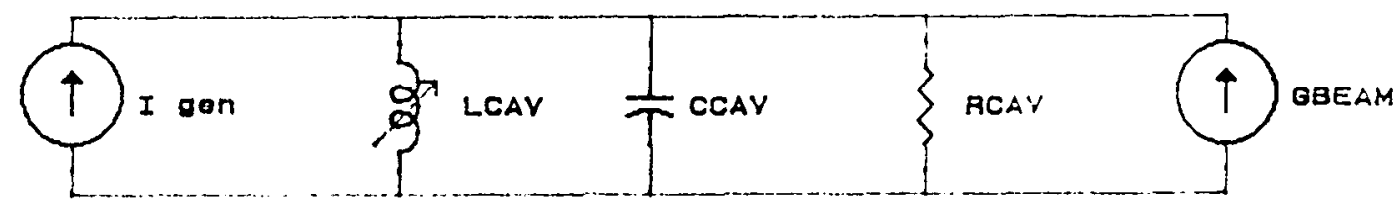

Fig. 1 - Equivalent Circuit of the Cavity - PA As Seen by the Beam

\begin{tabular}{l|l}
$F=2.5 \mathrm{MHz}$ & $\mathrm{F}=4.2 \mathrm{MHz}$ \\
\hline $\mathrm{L} 5.78 \mu \mathrm{H}$ & $2.05 \mu \mathrm{H}$ \\
$\mathrm{R} 1.82 \mathrm{k} \Omega$ & $1.39 \mathrm{k} \Omega$ \\
$\mathrm{I}_{\mathrm{PA}} 24.72 \mathrm{~A}$ & $32.24 \mathrm{~A}$ \\
& \\
\multicolumn{1}{c|}{$\mathrm{C}=700 \mathrm{pF}$}
\end{tabular}

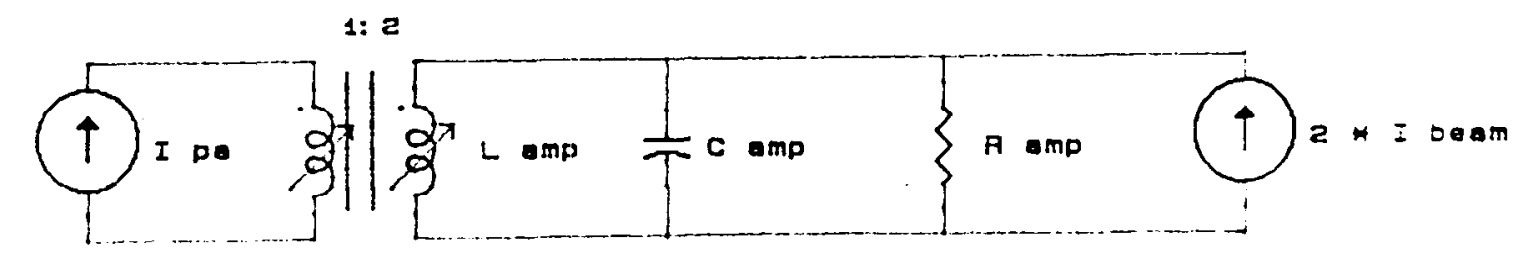

Fig. 2 - Equivalent Circuit of the Cavity - PA As Seen by the Power Amplifier 


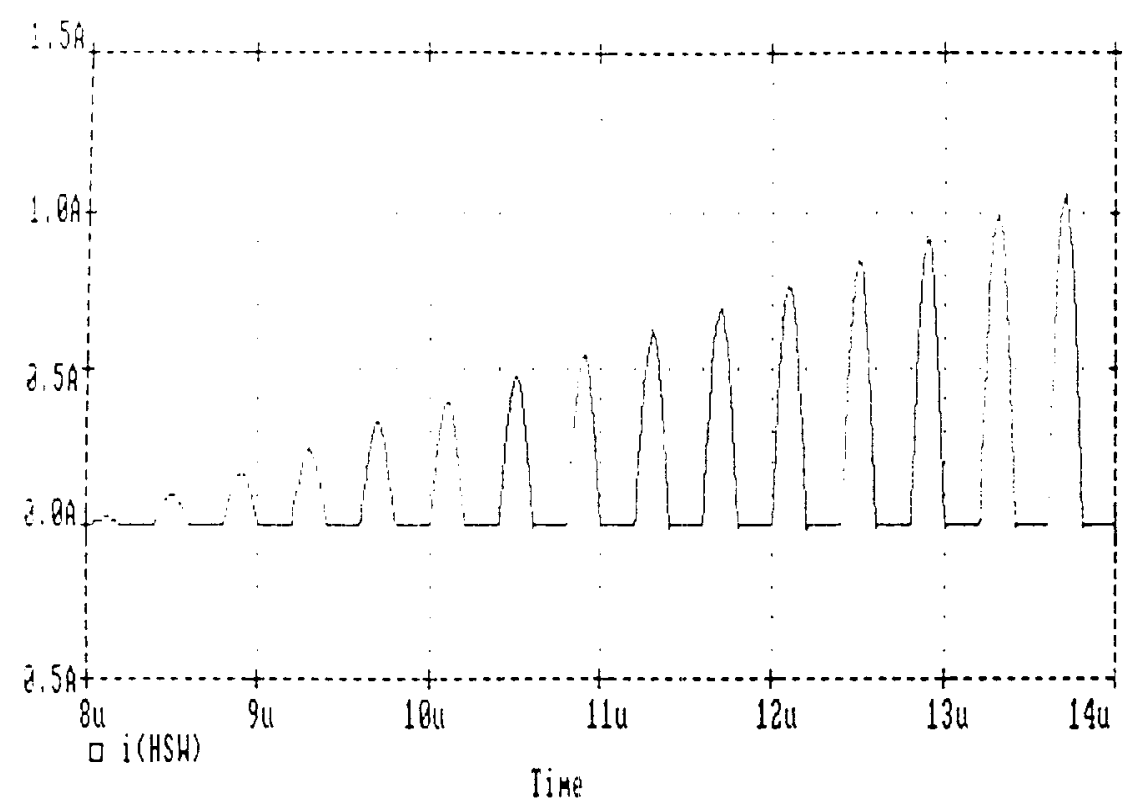

Fig. 3 - Beam Current at Injection in the Multiturn Scheme as Simulated in PSPICE
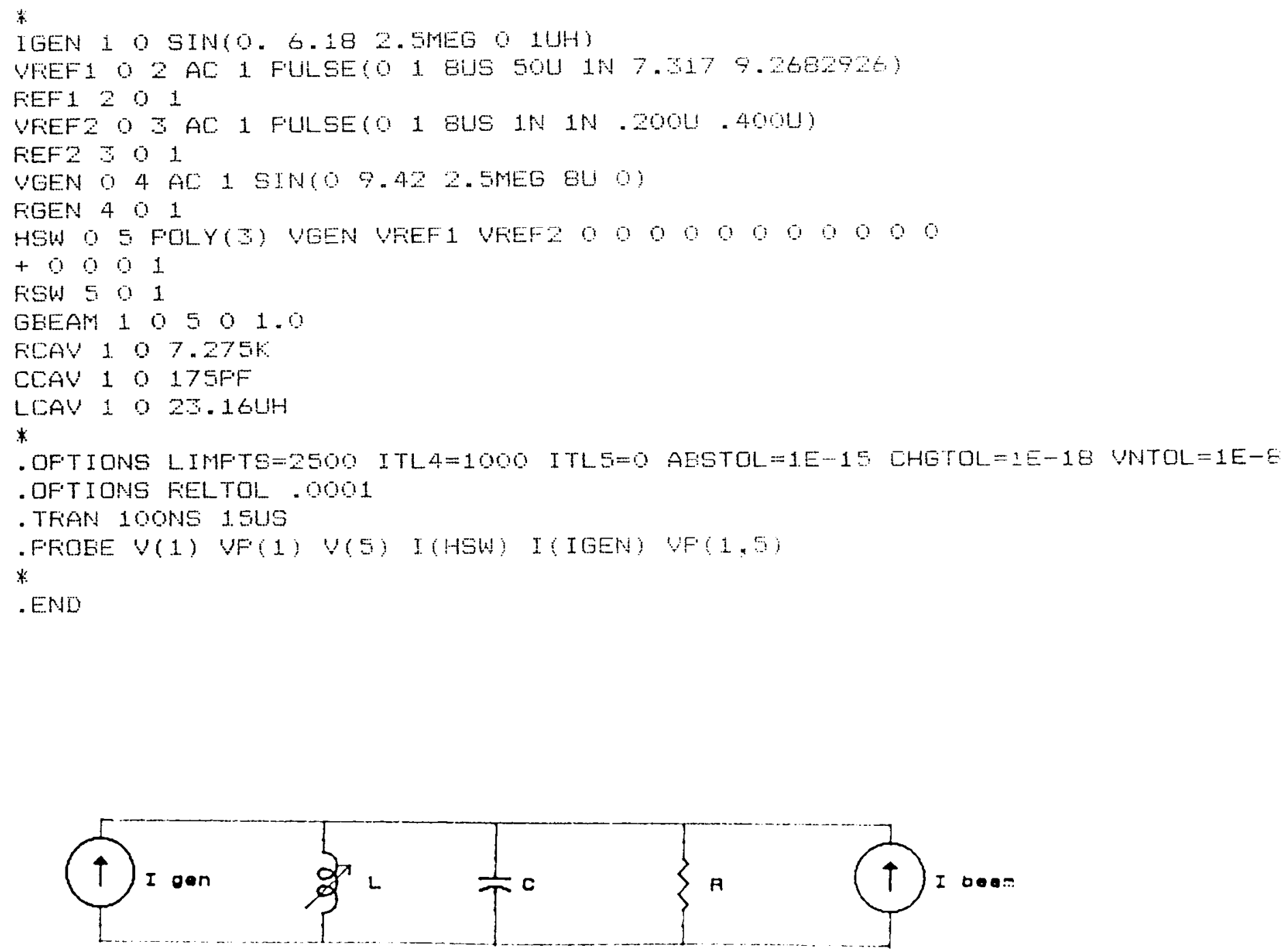

Fig. 4 - The PSPICE Model of the Transient Beam Loading at Injection 


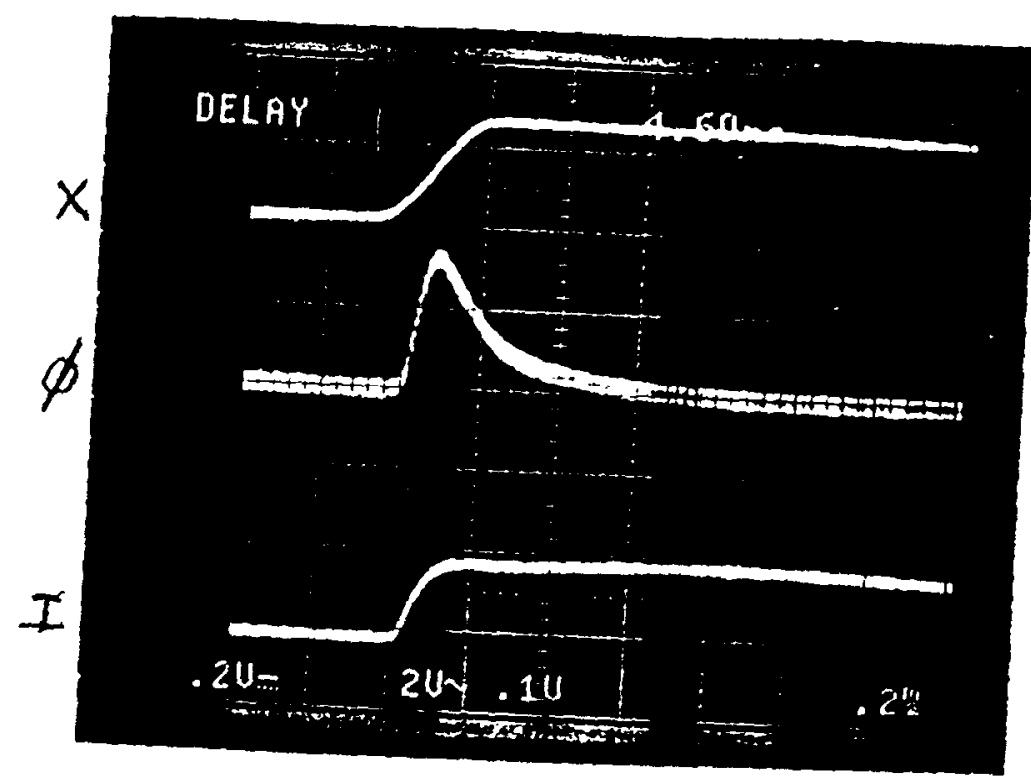

Fig. 5 - Tuning System Response to a Disturbance

$\mathrm{x}=$ disturbance

$\mathrm{PHI}=$ phase detector output $(9 \%$ div $)$

$\mathrm{I}=$ tuning current $(15 \mathrm{~A} /$ div. $)$

Time Scale $=200 \mu \mathrm{s} / \mathrm{div}$ 


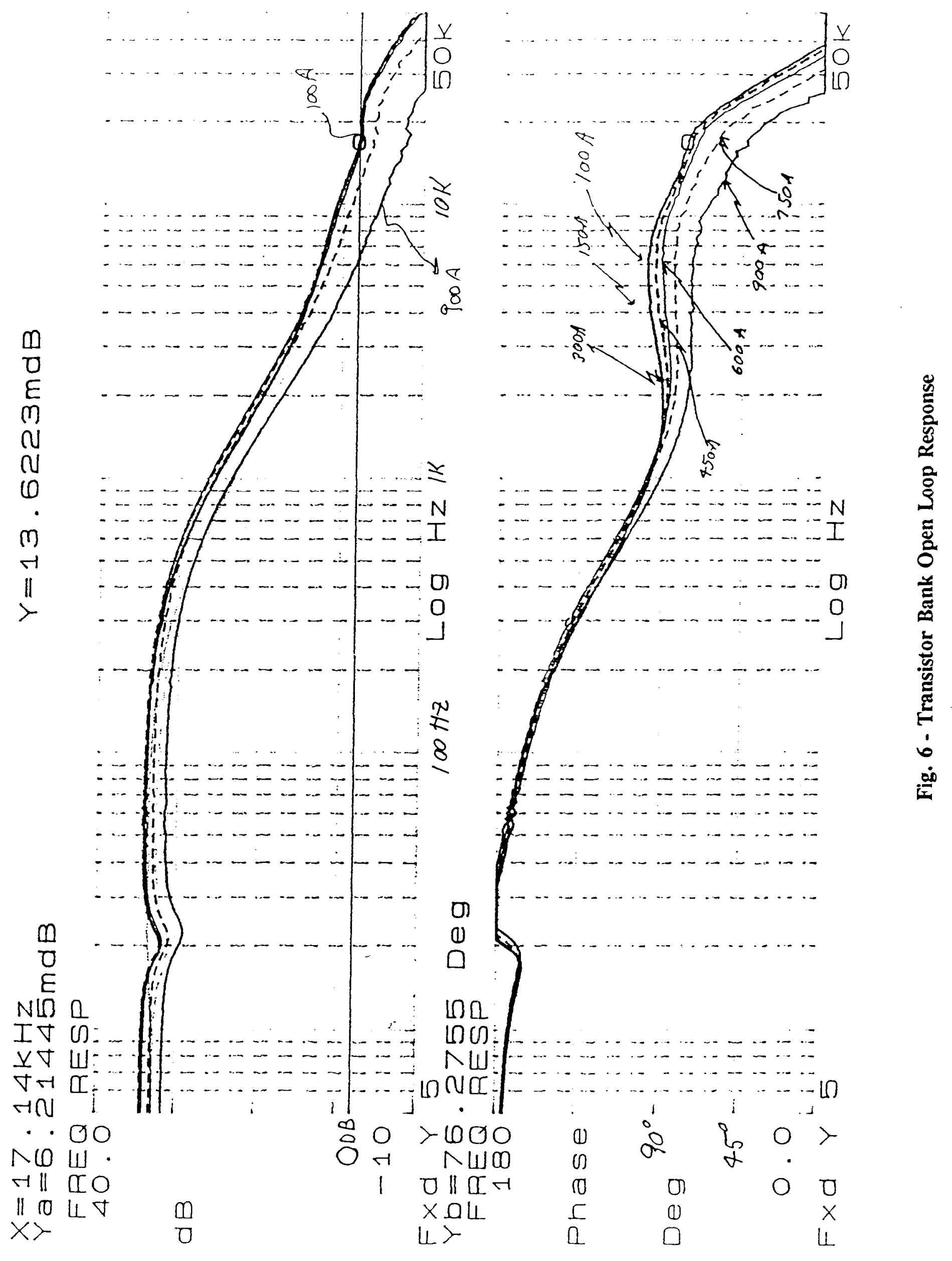

